\title{
MODELO GEOESPACIAL PARA O DESENVOLVIMENTO SUSTENTÁVEL DA
}

\author{
EXPANSÃO URBANA
}

Liane da Silva Bueno ${ }^{1}$

\begin{abstract}
RESUMO
Os problemas ambientais das cidades brasileiras exigem cada vez mais assumir uma postura diferenciada da tradicional. É necessário avaliar cada espaço que está sendo planejado, e desenvolver uma metodologia, estar prontos para decidir em favor de um futuro ecologicamente equilibrado e seguro. Este estudo visa a prevenção de riscos, o desenvolvimento da expansão urbana sustentável, a proteção dos ecossistemas, apoiando as decisões de planejamento de infraestrutura, bem como preparar-se para a busca de um espaço resiliente, este é o único que tem a capacidade de absorver e se recuperar eficientemente os efeitos de um desastre e de forma organizada, evitando que vidas e bens sejam perdidos. O resultado dessa pesquisa é um modelo a partir do estudo geoespacial aplicado na Ilha de Santa Catarina, sul do Brasil, considerando as características físicas, o zoneamento de áreas ambientalmente frágeis, regiões impróprias para intervenção urbana, oferecendo oportunidades para a revisão do plano diretor.
\end{abstract}

Palavras-chave: Expansão urbana. Uso e ocupação do solo. Modelo geoespacial. Ilha de Santa Catarina.

\section{ABSTRACT}

The environmental problems in Brazilian cities require increasingly assume a different position from the traditional. It is necessary to evaluate each space being planned, and develop a methodology, we are ready to decide in favor of a future ecologically balanced and secure. This study aims to prevent risks, the development of sustainable urban sprawl, protecting ecosystems, supporting planning decisions infrastructure, as well as prepare for the pursuit of a flexible space, this is the one that has the capacity to absorb and recover efficiently the effects of a disaster and in an organized manner, preventing lives and property are lost. The result of this research is a model from the study geospatial applied on the Island of Santa Catarina, southern Brazil, considering the physical characteristics,

\footnotetext{
${ }^{1}$ Engenheira Civil, Mestre em Engenharia Civil, Doutora em Engenharia de Produção. Docente da UNIARP.E-mail: civil@uniarp.edu.br.
} 
the zoning environmentally of fragile areas, the regions unsuitable for urban intervention, providing opportunities for the revision of the master plan.

Keywords: Urban environmental degradation. Law and land use planning. Urban interventions. Director plans. Resilient spaces.

\section{INTRODUÇÃO}

A preservação ambiental e a qualidade de vida com sustentabilidade requer uma consciência por parte da população e dos gestores das instituições responsáveis pela tomada de decisão. Nota-se que na busca pela qualidade de vida as pessoas têm procurado lugares pitorescos como a Ilha de Santa Catarina para viver. Esse processo de urbanização tem ocasionado um crescimento desordenado não só nas praias do litoral da Ilha, como também, na parte central, na qual vem atingindo toda região Metropolitana, haja vista, a adequação de projetos específicos para a ocupação espacial, aprovados pelos órgãos de planejamento. Sabe-se que não há como frear esta tendência de aglomeração urbana em torno não só das praias como em todo território da Ilha, sendo que as próprias características geográficas favorecem o processo de expansão urbana.

Portanto, confirma-se a necessidade de se realizar um estudo dessa situação, objetivando subsidiar uma legislação específica que oriente o processo, a médio e em longo prazo.

Desde 1988 a Constituição da República Federativa do Brasil obrigou os municípios com mais de 20.000 habitantes a ter um Plano Diretor, inserindo o instrumento urbanístico na política urbana. Sendo que em 2001 o Estatuto da Cidade, determina para os municípios que ainda não possuem o plano, que o façam num período máximo de cinco anos.

O Plano Diretor define as políticas públicas urbanas de transporte, zoneamento, provisões de habitações de interesse social etc. Mas, como um instrumento de política pública, o plano diretor assume inúmeras feições, pois vem sendo usado como instrumento da burguesia nas grandes cidades, apoiando-se num estado estruturado para ratificar a hegemonia das classes dominantes. Complementa-se que para realizar-se Planos Diretores frente a atual conjuntura de nossas cidades, é necessário assumir um novo olhar, na qual venha resgatar valores, numa sociedade que se encontra voltada ao consumismo; que procura 
assumir posições de poder a qualquer preço, quando se percebe a total inobservância de determinadas intervenções ambientais em que os ecossistemas são alterados e até mesmo esgotados. Tal realidade vem expor à riscos, comprometendo a qualidade de vida das pessoas e criando riscos ambientais. Portanto, frente à necessidade de se buscar iniciativas técnicas que venham resultar na sustentabilidade de nossas cidades, através de métodos que tenham a finalidade de harmonizar a distribuição consciente do espaço bem como, conhecer suas características e valor ambiental, para preparar espaços resilientes, teve origem esta pesquisa.

\section{OBJETIVO}

Este trabalho tem como objetivo desenvolver um modelo geoespacial visando o desenvolvimento sustentável da expansão urbana, tendo como estudo de caso a Ilha de Santa Catarina/Brasil.

\section{METODOLOGIA}

Esta pesquisa deu-se a partir da necessidade de se buscar um modelo para subsidiar a elaboração e a atualização de Planos Diretores frente ao crescente avanço do processo da expansão urbana e o comprometimento ambiental que esta intervenção pode causar nas áreas por ela atingida.

Sabe-se que a qualidade ambiental está condicionada a tomada de decisão dos planejadores municipais, ou seja, aos critérios por eles adotados nos quais vêm determinar e direcionar o futuro dos municípios.

Sendo as informações ambientais imprescindíveis para subsidiar a elaboração e atualização de Planos Diretores, o presente trabalho atende às características da pesquisa qualitativa através de um estudo de caso.

Na pesquisa qualitativa conforme Silva e Menezes (2001, p.20):

há uma relação dinâmica entre o mundo real e o sujeito, isto é, um vínculo indissociável entre o mundo objetivo e a subjetividade do sujeito que não pode ser traduzido em números. A interpretação dos fenômenos e a atribuição de significados são básicas no processo de pesquisa qualitativa. Não requer o uso de métodos e técnicas estatísticas. O ambiente natural é a fonte direta para coleta de dados e 
o pesquisador é o instrumento-chave. É descritiva. Os pesquisadores tendem a analisar seus dados indutivamente. O processo e seu significado são os focos principais de abordagem.

O procedimento metodológico, obedece as seguintes etapas: Definição da Pesquisa e Seleção da Área de Estudo; Seleção e Aquisição de Materiais Bibliográfico e Cartográfico; Reconhecimento da Área de Estudo, Estudo do Plano Diretor de Florianópolis; Definição dos Critérios Adotados para a Pesquisa a partir das informações geoambientais da área de estudo e a técnica de Geoprocessamento aplicado a partir do Sistema de Informações Geográficas, utilizando-se os seguintes documentos cartográficos: Mapa das Unidades Espaciais de Planejamento; Mapa das Unidades de Conservação; Mapa de Declividade; Mapa de Zonas Geoambientais e Derivados de Lineamentos Estruturais, Mapa de Zonas Geoambientais e Derivados de Traços de Juntas, Mapa de Zonas Geoambientais e Linhas de Forma; Mapa de Unidades Integradas; Mapa de Zoneamento Territorial do Uso e Ocupação do Solo da Ilha de Santa Catarina.

\section{ÁREA DE ESTUDO}

O estudo e aplicação do modelo foi realizado na Ilha de Santa Catarina, região sul do Brasil, situada entre os paralelos de 27010' e 27050' de latitude sul e no meridiano de 4825' e 48오' de longitude oeste de Greenwich.

Salienta-se que a seleção da Ilha, como aplicação do modelo proposto, deve-se ao fato de que a mesma apresenta problemas de ocupação em áreas de encosta, em locais de baixa declividade e até mesmo em ecossistemas, apontando situações de áreas de ocupação urbana com fatores de risco, conforme observado por Bueno(2000), a necessidade de garantir qualidade de vida e segurança da população, e as características peculiares paisagísticas que deve ser preservada.

\section{GEOPROCESSAMENTO}

Optou-se pelas técnicas de Geoprocessamento através do Sistema de Informações Geográficas como ferramenta para a automatização dos processos cartográficos, armazenamento, recuperação, manipulação e análise de dados.

O termo Geoprocessamento denota a disciplina do conhecimento, que 
utiliza técnicas matemáticas e computacionais, para o tratamento da informação geográfica, influenciando de maneira crescente as áreas de Cartografia, Análise de Recursos Naturais, Transportes, Comunicações, Energia e Planejamento Urbano/Regional e outros (GEO, 2003).

Para INPE (2003), o geoprocessamento pode ser definido como um conjunto de tecnologias voltadas a coleta e tratamento de informações espaciais para um objetivo específico. Assim as atividades que envolvem o geoprocessamento são executadas por sistemas específicos para cada aplicação. Esses sistemas são mais comumente tratados como Sistemas de Informação Geográfica (SIG).

Com o emprego das técnicas de Geoprocessamento aplicado a partir do Sistema de Informações Geográficas, realizou-se os cruzamentos dos dados geoespaciais cartográficos, tendo como mapa base de referência aos cruzamentos - Mapa das Unidades Espaciais de Planejamento vigente, utilizados pelos órgãos administrativos municipais de Florianópolis. A partir do referido mapa base, incluiuse a integração das informações georreferenciadas das Unidades de Conservação, as Declividades; as Zonas Geoambientais e Derivados de Lineamentos Estruturais, as Zonas Geoambientais e Derivados de Traços de Juntas, assim como as Zonas Geoambientais e Linhas de Forma.

Observou-se que a integração resultante dos cruzamentos geoambientais das informações utilizadas para as análises, apresentaram algumas ocorrências. As frequências de ocorrências, critério definido na pesquisa, possibilitaram direcionar algumas classificações.

Para a classificação foi definido o critério do número de ocorrência dos fatores estruturais: freqüência de lineamentos, freqüência de intersecções de lineamentos, zonas de variação de máximos 1 , zonas de variação de máximos 2 , eixos de direções de máximos 1 e 2 e linhas de forma (altos/baixos estruturais), relacionados as classes de declividade: baixa, intermediária e alta, correspondendo na presente pesquisa as declividades baixas, intermediárias e altas respectivamente.

\section{Mapa das Unidades Espaciais de Planejamento}

O Mapa das Unidades Espaciais de Planejamento da Ilha de Santa Catarina 
(Wanka e Orth, 1996) apresenta os limites espaciais das regiões que compõem a Ilha de Santa Catarina. O referido mapa foi elaborado a partir da adaptação do mapa analógico UEP, IPUF(1996), na escala 1:25.000. Esse mapa, o qual contém 112 UEPs, servirá de base para a localização das zonas favoráveis ao uso e ocupação do solo.

\section{Mapa das Unidades de Conservação}

O Mapa das Unidades de Conservação da Ilha de Santa Catarina (Orth e Franceshi, 1998), contém informações relevantes que devem estar contempladas e respeitadas num Plano Diretor. Destaca-se que a partir da identificação espacial das áreas de conservação aliada a declividade e as propriedades do meio físico terse-á condições de se subsidiar um planejamento coerente e criterioso para as respectivas regiões.

\section{Mapa de Unidades Integradas}

Nesta etapa foi feita a superposição do Mapa das Unidades Espaciais de Planejamento com o Mapa das Unidades de Conservação, onde foram identificadas espacialmente as regiões pertencentes às áreas de conservação.

A superposição teve por objetivo localizar as unidades de conservação que são áreas protegidas por lei - áreas intocáveis no que tange a intervenção antrópica - no Mapa das Unidades Espaciais de Planejamento.

\section{Mapa de Declividade}

Nesta etapa foi utilizado o Mapa de Declividade de Bastos (2002) - Figura 6, elaborado através de manipulações digitais do Mapa Planialtimétrico da Ilha de Santa Catarina, indicando a inclinação do terreno e evidenciando as áreas com maiores riscos de erosão e perda de solos bem como, as áreas sujeitas à inundação.

Esse mapa, apresenta três classes de declividades ( $<2 \%, 2 \%$ a $30 \%,>30 \%)$, mostrando os intervalos de restrição para o parcelamento do solo para fins urbanos ou de expansão urbana.

O Mapa de Declividade, além de mostrar como se apresenta a distribuição 
das declividades, permite também inferir riscos que as mesmas oferecem a determinadas intervenções antrópicas (BUENO, 2000).

Destaca-se que a inclusão desse Mapa para a realização deste estudo, fezse necessário a fim de se identificar juntamente com as propriedades do meio físico as zonas favoráveis à ocupação urbana.

\section{Mapa de Zonas Geoambientais e Derivados de Lineamentos Estruturais}

Como zona geoambiental, entende-se as áreas que correspondem a grupos de rochas com diferenças de ordem genética e de evolução tectônica (FRANZONI, 2000).

O Mapa de Zonas Geoambientais e Derivados de Lineamentos Estruturais de Franzoni (2000), foi elaborado a partir da superposição do Mapa de Zonas Geoambientais com o Mapa de Lineamentos Estruturais e Derivados o qual representa as descontinuidades penetrativas na crosta terrestre e que podem ser interpretadas como falhamentos quando possuem movimentos relativos aparentes como, falhas normais, inversas, reversas, transcorrentes e/ou direcionais, ou como discordâncias e/ou deformacionais.

Para o autor, essas estruturas manifestam-se na superfície como traços contínuos ou descontínuos, retilíneos ou curvilíneos, bem como, sinuosos dependendo do tipo de estrutura que representa.

\section{Mapa de Zonas Geoambientais e Derivados de Traços de Juntas}

O Mapa de Zonas Geoambientais e Derivados de Traços de Juntas de Franzoni (2000), apresentado na Figura 8, foi elaborado a partir da superposição do Mapa de Zonas Geoambientais com o Mapa de Traços de Juntas e Derivados no qual representa as feições lineares de drenagem que interpretadas em produtos de sensoriamento remoto sob o ponto de vista geológico são chamadas de traços de juntas (FRANZONI, 2000).

\section{Mapa de Zonas Geoambientais e Linhas de Forma}

O Mapa de Zonas Geoambientais e Linhas de Forma (FRANZONI, 2000), resultado da superposição do Mapa de Zonas Geoambientais e Mapa de Linhas de 
Forma, foi obtido a partir da simetria da rede de drenagem a qual indicada os mergulhos dos estratos rochosos, mostrando as áreas que apresentam altos e baixos estruturais.

Para o autor as linhas de forma são linhas de contorno estrutural não cotadas, provenientes de um alívio de pressão, que foram consideradas como resultantes de uma fase final de cisalhamento, originando os baixos e altos estruturais.

INFORMAÇÕES GEOAMBIENTAIS

Diante do comprometimento ambiental com que a expansão urbana tem se processado, na maior parte das cidades brasileiras, enfatiza-se a necessidade de observar a importância e o valor das informações geoambientais para as tomadas de decisões e, conseqüentemente, a realização do planejamento ambiental urbano e de espaços resilientes.

Estudos e trabalhos práticos relacionados ao uso e ocupação do solo vêm sendo realizados, valendo-se de novas metodologias e técnicas cada vez mais avançadas, objetivando a caracterização do meio físico como subsídio ao planejamento e gestão dos espaços.

CREA (2002) relata que o crescente crescimento demográfico nos centros urbanos, aliado a ausência de infra-estrutura, tem provocado nos últimos anos conseqüências desastrosas para o meio ambiente. Portanto, ordenar o espaço para fins urbanos, implica planejar sem impactar o ambiente, sem comprometer os recursos renováveis.

Franzoni (2000) em sua pesquisa sobre unidades geoambientais da Ilha de Santa Catarina, confere-se da importância do conhecimento das informações sobre as limitações do ambiente, para que se realize o controle ou gestão ambiental.

Sabe-se que uma das formas de se representar as informações geoambientais é através de um zoneamento onde todas as características das diferentes unidades de um determinado espaço são conhecidas. O zoneamento geoambiental, como fundamento no diagnóstico integrado da paisagem, caracteriza, descreve, classifica, sintetiza e espacializa as diferentes unidades, identificando suas potencialidades e restrições de uso (Cardenas, 1999). 
Os efeitos ambientais que devem receber maior atenção, referem-se às características do ecossistema a ser afetado; a localização de áreas de preservação permanente; áreas de interesse especial, tais como as de proteção de mananciais, de patrimônio cultural, histórico, paisagístico e arqueológico, bem como os parques nacionais, estaduais, e municipais, etc.; a transposição de áreas urbanas; as modificações da paisagem por cortes, aterros e túneis e, até mesmo, os impactos indiretos das obras sobre os locais interligados, bem como os impactos provocados por certas intervenções antrópicas em âmbito local e nas áreas de entorno.

Com base em estudos realizados através de levantamentos setoriais e/ou integrado dos recursos naturais e do meio ambiente, utilizando técnicas de sensoriamento remoto e geoprocessamento, pode-se adotar procedimentos metodológicos capazes de conduzir à delimitação de unidades geoambientais em consonância com proposições geossistêmicas.

As unidades geoambientais discriminam o potencial e limitações de uso dos recursos naturais; as condições ecodinâmicas e a vulnerabilidade, bem como, o uso compatível visando sua sustentabilidade.

Estudos envolvendo as questões ambientais, variam desde as investigações de suas características físicas, composições geoambientais até a problematização referente à ocupação urbana.

Bueno (2000) realizou o mapeamento de áreas de ocupação urbana com fatores de risco, no Bairro Córrego Grande e seu entorno, localizado no município de Florianópolis, classificando-as e direcionando-as quanto às medidas a serem tomadas para viabilizar a ocupação urbana.

A autora afirma que, qualquer intervenção no ambiente, sempre provocará algum impacto, o que vem confirmar a necessidade de se obter o conhecimento das características do meio físico, a fim de subsidiar o planejamento urbano durante a tomada de decisão.

USO E OCUPAÇÃO DO SOLO

Vários estudos e trabalhos práticos relacionados ao uso e ocupação do solo vêm sendo realizados, valendo-se de novas metodologias e técnicas cada vez 
mais avançadas, objetivando a caracterização do meio físico como subsídio ao planejamento de áreas urbanas com fatores de risco (Bueno, 2003).

Sabe-se que o modelo de desenvolvimento ambiental que vem ocorrendo nas cidades, é caracterizado pela degradação ambiental. Esta degradação é o reflexo dos impactos decorrentes da urbanização predatória sobre o ecossistema. Confirma-se a ausência de políticas que venham ordenar o uso e ocupação do solo. Em São Paulo, por exemplo, a ocupação urbana vem atingindo, como última alternativa, as áreas de proteção de mananciais (JACOBI, 2000).

Segundo Suertegaray (2000), se a ocupação do solo ocorre de forma desordenada, e não controlada, a quantidade de adversidades ambientais decorrentes é grande. Exemplos dessas adversidades são: perdas substanciais da biodiversidade da flora e fauna, de cidades inundadas pela água da chuva, da desertificação de extensas faixas de solo, da contaminação de corpos hídricos, de desmoronamento e desbarrancamentos de encostas frágeis.

Ao se identificar a compatibilidade de usos e ocupações adequadas em um determinado ambiente, defini-se que existem áreas que não podem ser ocupadas por serem inundáveis ou sujeitas a outros riscos, e as que não podem ser desmatadas por apresentarem fragilidades, tais como, altas declividades. Existem também as que possuem vocações turísticas, por apresentarem belezas cênicas, as que não devem ser urbanas, mas sim agrícolas e as que devem ser totalmente preservadas.

A irracionalidade de forma imediatista da ocupação do solo atinge as raias da incoerência, visto que o processo se desenvolve com total ignorância ou desprezo pelo que ocorre ou ocorrerá a sua volta. Com o objetivo maior de explorar com exaustão os recursos disponíveis, omite-se a implantação de dispositivos que possam atenuar os impactos ambientais nas áreas urbanas (SILVA, 1989).

O descaso fadado pela inobservância das características dos espaços para ocupação urbana, tem provocado inúmeras ocorrências de desmoronamentos, grandes enxurradas e inundações, causando perdas de vidas, muitas vezes de boa parte de famílias inteiras, 
O PLANO DIRETOR

O Plano Diretor, mais que uma peça técnica, é um instrumento político, cuja maior virtude deve ser a de dar visibilidade e transparência à política urbana. $\mathrm{Na}$ medida em que se tornam públicas as diretrizes e prioridades de desenvolvimento e expansão urbana, a sociedade pode intervir e participar da gestão. Cada cidade possui uma lógica de crescimento, e o Plano deve democratizar e dar transparência ao processo. Em suma, o Plano Diretor deve ter o papel de livro de regras no jogo da cidadania.

Maricato (2001), em suas investigações sobre alternativas para crises urbanas nas cidades brasileiras, menciona a necessidade do Plano Diretor como zoneamento de uso do solo, bem como a necessidade de direcionar áreas favoráveis para investimentos imobiliários e, a determinação de áreas para projetos de rede viária.

Mota (apud DEBETIR et al 2002) de acordo com a qual o Plano Diretor é um instrumento básico de orientação do desenvolvimento e expansão urbana, devendo conter as diretrizes para o crescimento econômico e social ecologicamente equilibrado.

Arruda et al (2002) mencionam que a política urbana deve empenhar-se para a ordenação de um espaço equilibrado e saudável, coordenando todas as transformações do ambiente construído, visando o bem estar dos munícipes e a promoção do pleno desenvolvimento das funções sociais da cidade.

Segundo Lima (2002), no estudo realizado sobre a influência do Plano Diretor para os municípios brasileiros de pequeno porte, constata-se que, o Plano Diretor do município é a peça fundamental sobre a qual se apóiam todas as ações, quer dos munícipes no exercício de suas cidadanias, quer dos Poderes Públicos na condução das soluções dos problemas existentes. Ressalta, o referido autor, que para o pleno desenvolvimento das funções da cidade e a garantia do bem-estar de seus habitantes é imprescindível que cada membro da comunidade faça valer os seus direitos no exercício da cidadania, cumprindo primeiramente as suas obrigações como cidadãos do município e, em segundo lugar, exigindo dos Poderes Públicos tudo aquilo que é assegurado por Lei, principalmente no que diz respeito aos aspectos preventivos do controle ambiental. 
As cidades são uma radiografia explícita das conjunturas econômicas, sociais e políticas. Constituem um espaço múltiplo e diversificada, a riqueza está em seus conflitos e na maneira como se lida com eles. Seus tempos também são diferentes. Duas ou três décadas é o tempo que leva a consolidação urbana.

O Plano Diretor, por esta razão, não pode ser estanque, mas sim capaz de assimilar as mudanças de rumo que fatalmente ocorrerão.

O homem recria o ambiente e este é um desafio fantástico, porque é preciso possibilitar a qualificação do espaço urbano sem esquecer, que somos todos agentes desta mudança. Por isto é essencial que os cidadãos participem e ajudem a interpretar a cidade para que seja possível trabalhar com as mais diferentes visões. A cidade precisa ser pensada e preparada como o cenário da vida (BURMEISTER, 2002).

\section{ESPAÇOS RESILIENTES NO AMBIENTE URBANO}

Para resiliência em espaços passíveis a ocupação urbana, requer que se torne público um zoneamento na qual venha proporcionar a visualização de áreas vulneráveis a problemas ambientais sujeitas a inundações, desmoronamentos, como forma de planejar intervenções antrópicas no meio urbano, ou seja, o desenvolvimento urbano voltado a segurança, ao socioambiental e a sustentabilidade,. O comprometimento dos ecossistemas resultantes de diversas intervenções poderá levar o ambiente ao seu limite de resiliência. Portanto, caberá ao estado e a população tomarem iniciativas mitigadoras a fim de aumentar a capacidade de recuperação ambiental, contendo assim, o seu processo de esgotamento. Segundo Zancheti (2003), entende-se por resiliência a capacidade de um sistema ambiental manter sua estrutura e padrão de comportamento diante de distúrbios ou impacto externo (stress).

Com as mudanças climáticas globais, as cidades tendem a ser atingidas por fenômenos climáticos extremos de maior frequência e intensidade. Tendo em vista a tendência global de concentração da população nas cidades, o planejamento urbano precisa incorporar o conhecimento das vulnerabilidades e dos riscos aos quais a população está sujeita para poder propor medidas de mitigação e adaptação que aumentem a resiliência urbana, que é a capacidade de absorver perturbações mantendo seu funcionamento normal (IPCC, 2007). Caso 
contrário, as cidades se transformarão em armadilhas com imenso potencial para os desastres.

Tem-se o exemplo das inundações ocorridas em Nova Orleans/EUA, quando o furacão Katrina destruiu o sistema de diques em 2005, os deslizamentos da Região Serrana do Rio de Janeiro/Brasil, em 2011, com assentamentos humanos em áreas de risco, assim como o modelo de urbanização de Blumenau SC/Sul do Brasil, é baseado na ocupação e aterro dos fundos de vale, áreas inundáveis por natureza; no corte de morros para a abertura de ruas e para edificações; na retificação e tubulação de cursos d'água; e na supressão da vegetação das encostas, conforme menciona (Siebert, 2013).

A citada autora, em seu trabalho a respeito do estudo da resiliência urbana para planejar as cidades para enfrentar os fenômenos climáticos extremos, entende que as cidades brasileiras, impermeabilizadas entram em colapso a cada chuva mais intensa, com áreas inundáveis ocupadas, com rede de drenagem mal dimensionadas, encostas desestabilizadas, nossas cidades estão despreparadas para conviver com fenômenos climáticos intensos. Falta-lhes a resiliência urbana, a capacidade de continuar operacionar durante períodos de chuva, seca, frio, calor, etc, adaptando-se ao stress e às modificações impostas do exterior.

\section{RESULTADOS E DISCUSSÃO}

Buscando-se a resiliência urbana, em espaços propensos a riscos ambientais, ou seja, com características territoriais que apresentam limitações de uso e ocupação, criou-se um modelo para proporcionar a visualização geoespacial destas áreas. Propor um zoneamento, para apoiar o planejamento voltado a mitigação e a prevenção do uso e ocupação urbana, a partir de informações técnicas geoambientais dos espaços, assim como uma ferramenta para direcionar a identificação, análise, planejamento e gestão de espaços resilientes para a intervenção urbana.

Realizou-se a pesquisa na ilha de Santa Catarina, a partir das análises geoambientais, qual sejam, unidades de conservação ambiental, declividade e as unidades extraídas das análises das informações do meio físico, obtidas através dos mapas geoambientais de derivados de lineamentos estruturais, derivados de traços 
de juntas, bem como as zonas de linhas de forma, sendo estas características da fundamentação indicadas no modelo proposto. Assim sendo, obteve-se como resultado dos cruzamentos dos referidos dados cartográficos o mapa de zoneamento territorial para fins de uso e ocupação do solo da Iha de Santa Catarina. Tem-se que o mapa de zoneamento apresenta informações que podem afetar tecnicamente, ambientalmente e economicamente o processo de expansão urbana, devendo ser utilizado como apoio na fase de elaboração e atualização de Planos Diretores.

As informações possibilitaram a identificação das seguintes propriedades do meio físico:

Frequência de lineamentos estruturais; frequência de intersecções de lineamentos estruturais; zonas de variação de máximos 1 e 2; altos e baixos estruturais, relacionadas às classes de declividade: baixas, intermediárias e altas.

Portanto, o modelo, resultante desta pesquisa, proporcionou identificar ocorrências de fragilidade ambiental em áreas caracterizadas como impróprias a ocupação urbana, o que veio atender ao objetivo da pesquisa, proporcionar um zoneamento para direcionar diretrizes quanto ao uso e ocupação do solo visando buscar espaços resilientes.

Sendo assim, obteve-se como resultado da aplicação do modelo proposto, a compartimentação da área de estudo em duas zonas territoriais: Zona Propícia à Ocupação Urbana (ZPO) e Zona Restrita à Ocupação Urbana (ZRO), conforme explicita a legenda Figura 01, do Mapa de Zoneamento Territorial para fins de Uso e Ocupação do Solo da Iha de Santa Catarina, Figura 02.

A divisão da área de estudo em zonas territoriais mostrou-se extremamente favorável, pois permitiu visualizar as regiões que apresentam propriedades físicas favoráveis a intervenções antrópicas e que por lei não são unidades de conservação (ZPO) e em regiões consideradas como de preservação permanente, agregadas as que demandam uma grande infra-estrutura (ZRO).

Através dos lineamentos estruturais podem ser definidas áreas de maior concentração de feições lineares que refletem as condições tectônicas impostas sobre o substrato rochoso local. Os lineamentos de maior porte são importantes indicadores geológicos de zonas de fraquezas na crosta terrestre, como falhas tectônicas profundas, que servem para transportar a água subterrânea para as 
áreas de recarga e, as fraturas menores por sua vez, servem para interconexão entre os sistemas de fraturas e, armazenamento de água nos espaços vazios das rochas.

Regiões com alta frequência de lineamentos estruturais e alta frequência de intersecções de lineamentos estruturais indicam áreas intensamente fraturadas e susceptíveis a uma meteriorização, ou seja, a um intemperismo muito forte sujeito a percolação de águas por essas regiões, logo tornando-se uma área sob o ponto de vista de estabilidade muito frágil.

Os máximos 1 e 2 de fraturamento correspondem as duas direções de maior frequência de fraturamento da área que junto com seus eixos indicam zonas tectonicamente muito ativas susceptíveis a escorregamentos e movimentos.

A correlação, altos estruturais (anticlinais) e baixos estruturais (sinclinais) com a topografia, indica áreas configuradas como alto estrutural e alto topográfico, baixo estrutural e alto topográfico, alto estrutural e baixo topográfico e, baixo estrutural e baixo topográfico.

No caso de uso e ocupação do solo a associação de alto estrutural e alto topográfico, favorece a drenabilidade. São áreas que apresentam o lençol freático geralmente profundo, baixa umidade, solos profundos e de fácil escavabilidade. Entretanto apresentam condição favorável a existência de fraturas, alto potencial de infiltração de fluidos, baixa capacidade de depuração, alta vulnerabilidade à contaminação subterrânea.

A ocorrência de áreas de baixo topográfico associado a alto estrutural tem como fator desfavorável ser um sistema altamente percolativo e baixa capacidade depuradora.

Nas áreas de baixo topográfico e baixo estrutural ocorrem sistema com características concentradoras, área de descarga de aqüífero, lençol freático superficial, presença de solos e sedimentos moles e ricos em matéria orgânica, alta concentração de argilas.

Tais análises de ocorrências, resultaram a determinação das zonas e subzonas conforme mostra a Figura01. 


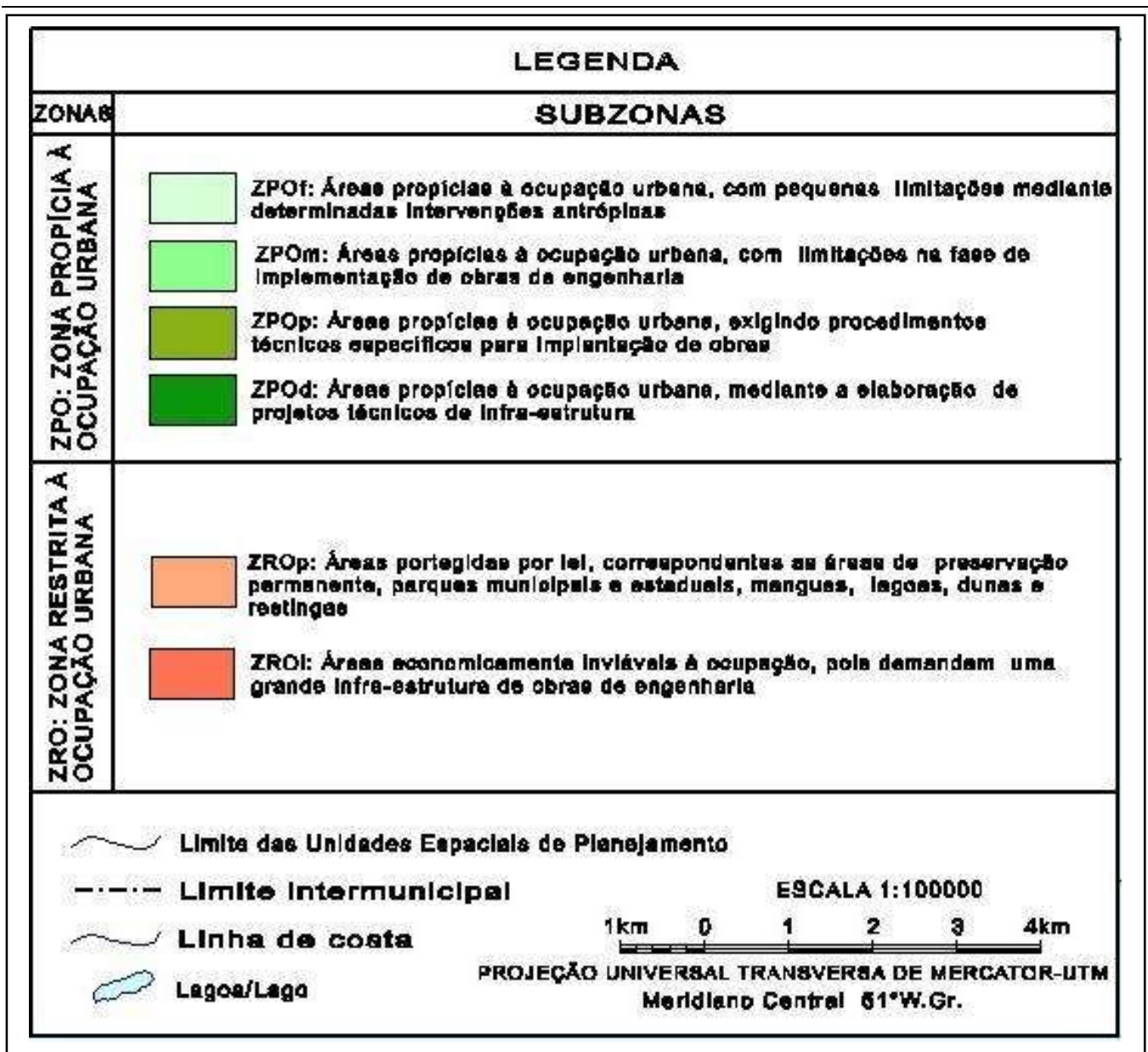

Figura 01: Detalhe da legenda do Mapa de Zoneamento Territorial para fins de Uso e Ocupação do Solo da Ilha de Santa Catarina Zonas e Subzonas 


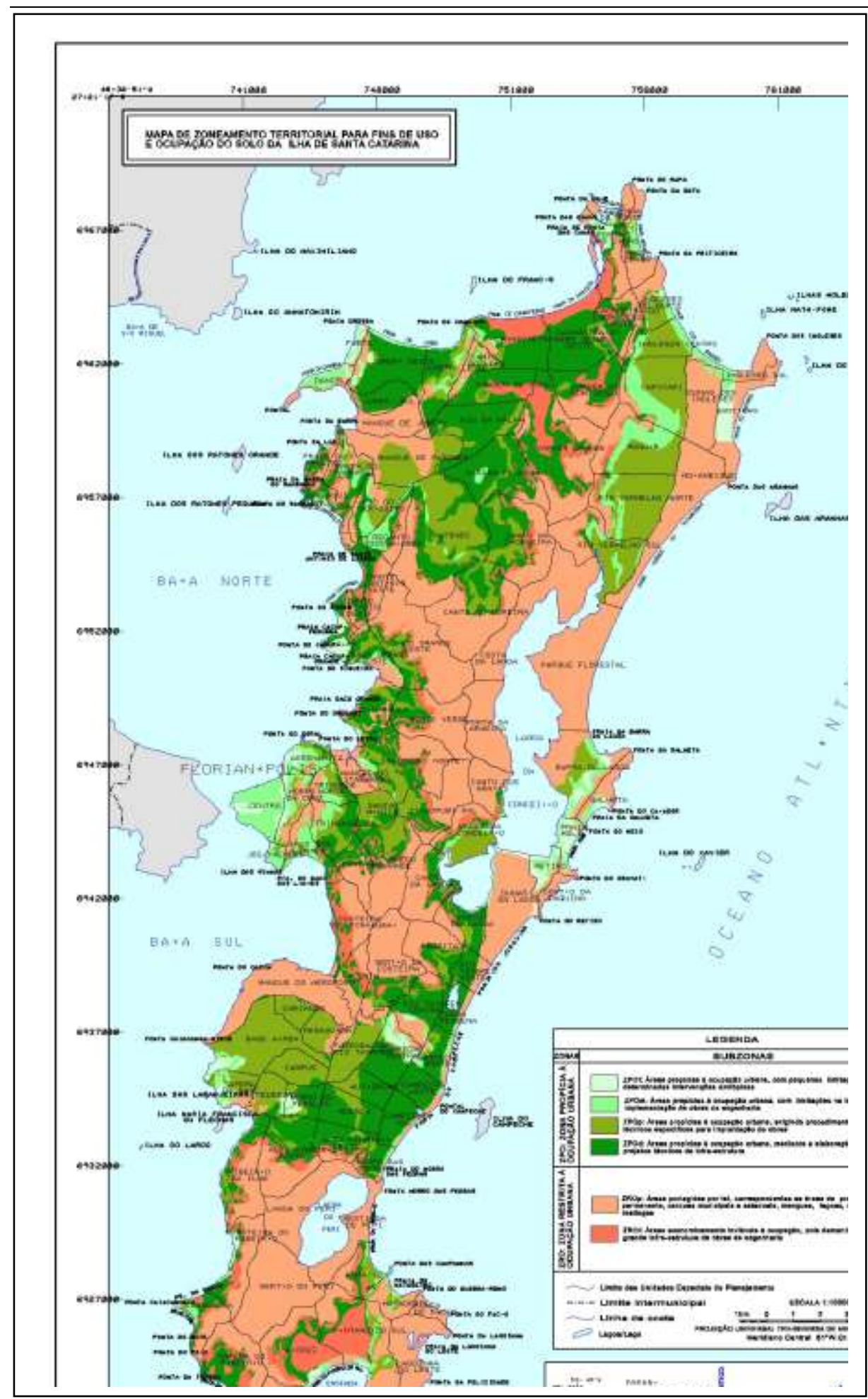

Figura 02: Mapa de Zoneamento Territorial para fins de Uso e Ocupação do Solo da Ilha de Santa Catarina 


\section{CONCLUSÃO}

O rápido crescimento das cidades associado à ausência de um planejamento adequado provoca graves desequilíbrios comprometendo a sustentabilidade do meio ambiente o que acarreta problemas econômicos, ambientais e sociais.

Assim, a necessidade de mapeamentos de recursos naturais renováveis e não renováveis, através de zoneamento territorial do uso e ocupação do solo, são indispensáveis na elaboração e a atualização de Planos Diretores.

Para tanto, o modelo apresentado é de relevância, pois propõe à integração dos dados ambientais tais como unidades de conservação, deformações tectônicas e suas respectivas estruturas, tais como: lineamentos estruturais, sistemas de juntas e altos/baixos estruturais relacionados a classes de declividade.

A identificação das características estruturais e ambientais nas unidades espaciais de planejamento através do zoneamento, resulta num importante documento de apoio para os tomadores de decisão quanto às diretrizes de orientação nos processos, tais como, expansão urbana, ecoturismo e deposição de rejeitos (aterros sanitários, lagoas de decantação e outras fontes potencialmente poluidoras).

A compartimentação da área de estudo em zonas territoriais mostrou-se extremamente favorável, pois permitiu separar a llha de Santa Catarina em regiões que apresentam propriedades físicas favoráveis a intervenções antrópicas e que por lei não são unidades de conservação, assim como as regiões consideradas como de preservação permanente, agregadas as que demandam uma grande infraestrutura. Esta visualização geoespacial vem corroborar com as premissas pela busca de espaços resilientes.

FIGUEIREDO (2013), menciona que entre os desafios colocados à cidade do século XXI, a cidade competi-tiva e a governação econômica que ela exige implicam transformações claramente disruptivas face aos modelos atuais. Destacando-se como frentes que a governação municipal avançou nas últimas duas décadas, o planejamento, a política ambiental e a intervenção social. Nesse contexto dos domínios, há aprendizagens e estruturas de intervenção que poten-ciarão respostas a novos desafios. Sendo que em termos organizacionais e 
de governo tudo tem de ser inventado, reforça que os desafios da competitividade urbana, suscitam transformações de uma gestão integradora.

Tem-se a concluir quanto a importância da informação geoespacial como forma de sustentação para busca do desenvolvimento sustentável e apoio a gestão das áreas resilientes enquanto gestão e atualização do conhecimento, da abrangência e direcionamento da tomada de decisão ao planejamento. O que possibilitará o estudo de medidas mitigadoras de riscos tal sejam, provenientes da forma de uso do solo ou das próprias características geoambientais prementes do lugar. O método como sendo componente norteador para estudo a respeito das cidades inteligentes, buscando um diferencial na forma de planejamento e gestão dos espaços urbanos, agregados as especificidades peculiares de cada município; base para a integração intersetorial relacionada ao desenvolvimento dos espaços urbanos; forma complementar as análises provenientes as diretrizes de Planos Diretores, propondo o cumprimento do aspecto social do método, quando direciona as zonas passíveis de ocupação, e as zonas impróprias a ocupação urbana, frente as restrições territoriais e o aspecto da sustentabilidade ambiental do zoneamento das áreas que indicam a necessidade de preservação, sejam elas protegidas ou não por Lei.

\section{REFERÊNCIAS}

ACSELRAD, H. A duração das cidades: sustentabilidade e risco nas políticas urbanas. Rio de Janeiro: DP\&A, 2001.

ADAMS, B. O Patrimônio de Florianópolis - Preservação Urbana: Gestão e Resgate de uma História. Florianópolis: Ed. da UFSC, 2002,192p.

AFONSO, C. M. Uso e Ocupação do Solo na Zona Costeira do Estado de São Paulo, Uma Análise Ambiental. São Paulo: Annablume, FAPESP, 1999, 180p.

ASCHER, F. Urbanismo para uma Cidade Mundial - Secretaria Municipal de Urbanismo. Rio de Janeiro, cad.1999. Disponível em: <http://www2.rio.rj.gov.br/paginas/noticias_caderno_ed1-4.htm>. Acesso em: 30 set. 2002.

BASSO, A. L. O Planejamento Democrático para a Cidade Sustentável. Porto Alegre: Ed.UFRGS, abril 2002. Disponível em: 
<http://www.ufrgs.br/editora/catalogogeraldescritivo.htm>. Acesso em: 24 abr.2002.

BASTOS, E. F. de. Mapa de Declividade. Trabalho de Conclusão de Curso-Engenharia Civil, UFSC, Florianópolis, 2002.

BUENO, Liane da Silva. Estudo em Áreas Urbanas com Fatores de Risco: O Caso do Bairro Córrego Grande - Florianópolis. 2000. Dissertação (Mestrado em Engenharia Civil) - Programa de Pós-Graduação em Engenharia Civil, UFSC, Florianópolis.

BUENO, Liane da Silva. Zoneamento Territorial do Uso e Ocupação do Solo Visando Elaboração e Atualização de Planos Diretores. 2003. 118p. Tese de Doutorado (Programa de Pós-Graduação em Engenharia de Produção). UFSC, Florianópolis.

BURMEISTER, N. A necessária releitura da cidade. Disponível em: <http://www.portoalegre.rs.gov.br/congresso/txts1.htm. Acesso em: 07 out. 2002.

CÂMARA, Gilberto; DAVIS, Clodoveu; MONTEIRO, Antônio Miguel Vieira. Introdução à Ciência da Geoinformação. Disponível em:

<http://www.dpi.inpe.br/gilberto/livro/introd/index.html>. Acesso em: maio 2013.

CARVALHO, Beatriz Nozari Ribeiro de. Um Sistema de Informações para a Prática do Gerenciamento e Planejamento Urbano. 2000. Tese (Doutorado em Engenharia de Produção) - Programa de Pós-Graduação em Engenharia de Produção, UFSC, Florianópolis.

CECCA. Qualidade de vida e cidadania: a construção de indicadores socioambientais da qualidade de vida em Florianópolis. Florianópolis: Cidade Futura, 2001.

CREA. Crescem as Cidades e os Problemas Ambientais. Disponível em: $<$ www.crearj.org.br/noticias2001/docs/not0038.htm>. Acesso em: 01 ag. 2002.

DEBETIR, E., ORTH, D.M.e PHILIPS, I.J. Legislação para Ordenação do Espaço Urbano. In: COBRAC - CONGRESSO BRASILEIRO DE CADASTRO TÉCNICO MULTIFINALITÁRIO, 5, 2002, Florianópolis, Anais... Florianópolis: COBRAC, 2002.

EMBRAPA. Novo Sistema Brasileiro de Classificação de Solos. Disponível em:<http://www.cnps.embrapa.br>. Acesso em: 10 mar. 2003.

FIGUEIREDO, António Manuel; PENABAD, Jose Manuel Pena; ÁLVAREZ, Enrique José Varela et al. Retos de la acciónde gobierno para las ciudades del siglo XXI Desafios da governação das cidades do século XXI. p.93-182. Ed.:Eixo Atlântico do 
Nordeste Peninsular, Porto. 2012. Disponível em:

http://www.eixoatlantico.com/sites/default/files/Retos\%20de\%20la\%20accion.pdf. Acesso em: 10 maio 2013.

FRANCO, M. de A. R. Planejamento Ambiental para a Cidade Sustentável. São Paulo - Annablume: FAPESP, 2000. 296 p.

FRANZONI, Ana Maria Bencciveni. Avaliação do Meio Físico para Fins de Planejamento Geoambiental no Traçado e Manutenção de Rede Viária: Ilha de Santa Catarina - SC. 2000. Tese (Doutorado em Geociências), UNESP, Rio Claro, SP.

FRANZONI, Ana Maria Bencciveni. Mapa de Zonas Geoambientais e Derivados de Lineamentos Estruturais. 2000. Tese (Doutorado em Geociências), UNESP, Rio Claro, SP.

FRANZONI, Ana Maria Bencciveni. Mapa de Zonas Geoambientais e Derivados de Traços de Juntas. 2000. Tese (Doutorado em Geociências), UNESP, Rio Claro, SP.

FRANZONI, Ana Maria Bencciveni. Mapa de Zonas Geoambientais e Derivados e Linhas de Forma. 2000. Tese (Doutorado em Geociências), UNESP, Rio Claro, SP.

HERCULANO, S.; PORTO, M.F.de S. Qualidade de Vida \& Riscos Ambientais. Niterói, R.J.: EdUFF, 2000.

GUEDES Jr, Alexandre. Mapeamento Hidrogeológico da Ilha de Santa Catarina através de técnicas de Geoprocessamento. 1999. Dissertação (Mestrado em Engenharia Civil) - Programa de Pós-Graduação em Engenharia Civil, UFSC, Florianópolis.

INPE. Sensoriamento Remoto e Geoprocessamento. Disponível em: <http.www.ltid.inpe.br/intro_sr.htm>. Acesso em: 20 jul. 2003.

IPUF. Instituto de Planejamento Urbano de Florianópolis. Disponível em:<http.www.ipuf.sc.gov.br>. Acesso em: 10 abr.2003.

MARICATO, E. Brasil, cidades alternativas para a crise urbana. Petrópolis, Rio de Janeiro: Vozes, 2001.

OLIVEIRA, A. B. de. A Análise Geomorfológica e Sócio Econômica como Instrumento de Ação no Planejamento Urbano. 1998. Dissertação (Mestrado em Geologia), UNESP, São Paulo. Disponível em: <http://www.rc.unesp.br/igce/geologia/gmam.html>. Acesso em: 24 abr. 2002. 
OLIVEIRA, F. A. de. Parâmetros Ambientais como Suporte ao Planejamento Urbano. http://www.projekte.org/meioambiente99/tema 03/text.htm. Acesso em:13 nov. 2000.

ORTH, D.; FRANCESHI, A. Mapa das Unidades de Conservação da llha de Santa Catarina. UFSC/CTC/ECV, 1996.

SANTOS, G. T. Integração de Informações Pedológicas, Geológicas e Geotécnicas Aplicadas ao Uso do Solo Urbano em Obras de Engenharia. 1997.Tese (Doutorado em Engenharia Metalúrgica, Minas e Metalúrgica) - Programa de Pós-Graduação em Engenharia Metalúrgica, Minas e Materiais, UFRGS.

SANTOS, L.M.dos. Informações Sobre Áreas de Risco Geotécnico e Pluviométrico como Contribuição ao Planejamento Urbano. Dissertação de Mestrado. Florianópolis, 2001.

SILVA, César Augusto Marques da; MODESTO, Francine. Cidades em zonas costeiras brasileiras: rumo à resiliência? Belém, PA, Brasil. . 2011.

SOUZA, M. L. Mudar a Cidade - Uma Introdução Crítica ao Planejamento e à Gestão Urbanos. Rio de Janeiro: Bertland Brasil, 2002, 560p.

SUERTEGARAY, D. M. A. Ambiente e Lugar no Urbano. A Grande Porto Alegre. Porto Alegre: Ed. Universidade/UFRGS, 2000.61p.

TEIXEIRA, J.P.; SILVA, J. E. O Futuro da Cidade - A Discussão Publica do Plano Diretor. Florianópolis: Instituto Cidade Futura, 1999.

VILLAÇA, F. Planos Diretores são Inoperantes. O Estadão, São Paulo, 2002. Disponível em:<http://www.estadao.com.br>. Acesso em: 27 set. 2002.

WANKA, J.;ORTH, D. Mapa das Unidades Espaciais de Planejamento da llha de Santa Catarina. UFSC/CTC/ENC, 1998.

ZANCHETI, S. M. Conservação Urbana. O Desenvolvimento Sustentável Urbano. Disponível em: $<$ http://www.urbanconservation.org/comentarios/coment_11.htm>. Acesso em 27 abr. 2003. 